\title{
Accelerated Life Test Design for Tractor Powertrain Front Axle
}

\author{
Azianti Ismail, ${ }^{1, a}$, Won Jung ${ }^{2}$ and Qiang Liu² \\ ${ }^{1}$ Faculty of Mechanical Engineering, Universiti Teknologi MARA Johor, Pasir Gudang campus, 81750 Johor, Malaysia \\ ${ }^{2}$ Department of Industrial and Management Engineering, Daegu University, 712-714 Gyeongsan, South Korea
}

\begin{abstract}
Accelerated Life Test (ALT) has been applied in the manufacturing for many years due to rapid changing technologies, more complex products, speedier product development, and more demanding customer requirements. These reasons have pushed the manufacturers to acquire reliability information faster. ALT allows reducing the time needed to show the reliability of the product. The purpose of this study is to design accelerated life testing which involved determination of normal test time, acceleration factor, acceleration test time, and finally experimental setup. This case study provides the basis for ALT designs for the tractor front axle based on customer usage and field failure analysis, which were conducted to estimate the current reliability, especially on the $\mathrm{B}_{10}$ life during the operational stage of the product. The accelerated life test conducted has guaranteed the $\mathrm{B}_{10}$ life of 4,000 hours with $90 \%$ confidence level for lesser time needed for testing to show the reliability of the front axle assembly.
\end{abstract}

\section{Introduction}

Engineers need to understand the usage environment, whereby the final product must endure to fulfil customer satisfaction. The response in an ALT is directly related to the lifetime of the product. Typically, ALT data is right censored because the test is terminated before all units fail. LuValle pointed out that it is likely to miss failure mode during accelerated testing efforts. This might happen if the true operating environments are not replicated during the test. It should be made to understand and to utilize the correct operating environment when planning and conducting accelerated testing to ensure minimum risk due to this consequence [1].

In the ALT, failures occurred more quickly from the actual environment in less time acquired. A controlled environment for the accelerated test was developed to simulate the use rather than testing in lengthy real-time tests. Important parameters for ALT are length of test, number of samples, confidence level, shape parameter $(\beta)$, and acceleration factor. Campean et al. have discussed on a generic approach to life prediction modeling for automotive components, which aims to establish a correlation between the degradation mechanism, customer usage profile and rig life testing to design ALT [2]. Meeker et al. have mentioned that with good characterization of field use conditions, it may be possible to use ALT results to predict the failure distribution in the field [3]. On the other hand, Attardi et al. have presented case study regarding the reliability analysis of some automotive components based on field failure warranty data in which can be used to design ALT [4].

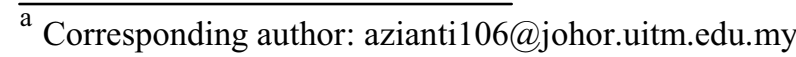

As for agricultural tractors, starting from the 1970s, studies were performed to estimate the fatigue life of a powertrain starting from a load spectrum derived from experimental measurements [5] and more recently, with the goal of estimating the loads during normal use of the tractor, defining the lifetime load spectra for agricultural transmissions [6]. The agricultural tractor market is constantly evolving, due to the changes caused by globalization that oblige farmers to reduce their production costs by using more specialized equipment and agricultural tractors. As a result, agricultural tractor manufacturers have to reduce time-to-market and development costs.

Agricultural tractors are used for many kinds of farm work under various soil and field conditions. The most common tractor uses, however, are tillage and ploughing. To take into account of the workload in the design of the tractor powertrain, the operational characteristics of tractors such as annual working hours, working speed, engaged gears, and load distribution must be analyzed. It is particularly important to know the number of cycles of loads and their magnitudes under all working conditions. Furthermore, the agricultural environment adds additional factors that complicate the development of reliability improvement of agricultural vehicles; for example, the diversity of areas of operation, the presence of obstacles in fields, uneven terrains, and the varied number of tasks to be carried out. Equally, soil quality, variation of crop physical characteristics and environmental conditions such as rain, fog, and dust need to be considered [7].

Among the main components of the tractor, the powertrain manufacturing cost is one third of the total cost of the finished product. Therefore, a high percentage 
of cost reduction can be achieved through the improvement of the manufacturing process of the powertrain due to the re-evaluation of its reliability and durability, and through the changes in its design. The powertrain is different from the exterior component of the tractor because, even with a simple breakdown, it requires a lengthy repair period and incurs a high cost. Thus, from the outset, the powertrain has to be manufactured with the best quality. The tractor powertrain assembly module can be divided into two parts, which are the transmission assembly with the rear axle assembly, and the front axle assembly. For this case study, the example of front axle assembly is shown.

\section{Methodology}

The data obtained from the analysis of usage environment for this case study based on questionnaires answered by the farmers, site visits and repair data from the service centers. Usage environment such as working conditions, variety of climatic conditions, environmental conditions; crop variety, soil, and water, were considered [8]. It also covered customer usage patterns to determine the possible failure modes, geographic location, purpose, and use of the tractors to provide the exact conditions. Potential failures occurred more quickly from the actual environment in less time acquired in ALT. In Figure 1, the methodology to design the ALT is shown.

Determine normal test time

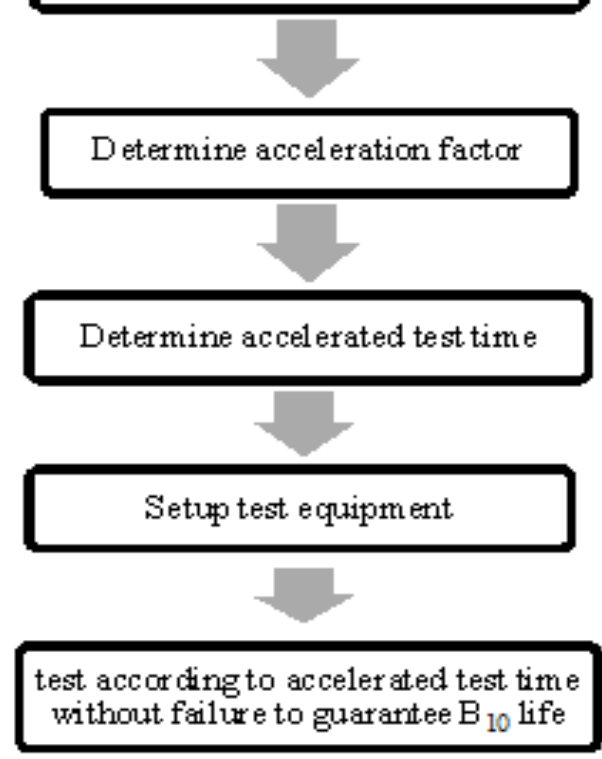

Figure 1. ALT design methodology.

Acceleration Factor (AF) can be found through testto-fail at different stress levels or may be from available relationships, such as Linear, Eyring, Inverse Power Law, Arrhenius and others. The AF provides a quantitative estimate of the relationship between the field condition and the test condition.

\subsection{Normal test time}

The first step was to determine the normal test time. For this case study, the normal test time (see Eq. (1)) for $t_{n}$ based on $\mathrm{B}_{10}$ life warranty for each part, $90 \%$ confidence level $(\mathrm{CL}=0.90$, $\mathrm{p}=0.10$ ), $\beta$ parameter (determined by Minitab analysis) is summarized in Table 1 . Normal test time calculation, $t_{n}$ is shown Eq. (1) [9]. The failure data of powertrain is in the form of failure observations from the truncated time of 3,000 hours. Using the field failure data, the failures were investigated using Minitab. In order to estimate the suitable statistical distribution of the field failure data, Anderson-Darling goodness of fit test was 582.361 and correlation coefficient for Weibull was 0.934 , in which it showed that it best suited for the distribution. $\beta$ shows how the failure rate is increased in time.

$$
t_{n}=B_{i}\left[\frac{\ln (1-C L)}{n \ln (1-p)}\right]^{\frac{1}{\beta}}
$$

\subsection{AF and Accelerated test time}

By applying the AF, accelerated test time could be compressed and the results could be obtained faster. The calculated accelerated test time was used in conducting the ALT for the powertrain. The test was designed or setup up to provide the same type of stress in the field based on the surveys of profile usage and field visits. The data from the tests were projected over the life cycle to mimic the normal operating field conditions.

Table 1. Normal test time for for front axle assembly.

\begin{tabular}{|c|c|c|}
\hline $\begin{array}{c}\text { Target lifetime } \\
\text { warranty, } \mathrm{B}_{10} \text { life }\end{array}$ & $\begin{array}{c}\text { Shape } \\
\text { parameter, } \\
\beta\end{array}$ & $\begin{array}{c}\text { Normal test } \\
\text { duration } t_{n}\end{array}$ \\
\hline 4,000 hours & 2.02 & 14,166 hours \\
\hline
\end{tabular}

In this environment, there were two AFs used; inverse power law and Arrhenius relationship. Many failures mechanisms exhibited time to failure models, which fitted the inverse power law, Arrhenius or a combined inverse power law-Arrhenius model [10]. The inverse power relationship is widely used to model life as a function of pressure-like accelerating variables (e.g., stress, pressure, voltage stress). This relationship is generally considered to be an empirical model because it has no formal basis from knowledge of the physics or chemistry of the modeled failure modes [11]. Thus the AF for the front axle assembly which is involved in gear loading and speed is:

$$
\begin{aligned}
& A F=\left(\frac{\operatorname{Torq}_{\text {test }}}{\operatorname{Torq}_{\text {field }}}\right)^{4}\left(\frac{\operatorname{Re} v_{\text {test }}}{\operatorname{Re} v_{\text {field }}}\right)^{1} \\
& \exp \left(\frac{E_{a}}{k}\left(\frac{1}{\text { TempMax }_{\text {field }}}-\frac{1}{\text { TempMax }_{\text {test }}}\right)\right)
\end{aligned}
$$

Torq $_{\text {test }}$ is the accelerated test torque (kgf.m), and Torq $q_{\text {field }}$ is the torque in the normal condition gathered from field data (kgf.m). Rev test is the accelerated test speed (rpm), 
and $R e v_{\text {field }}$ is the speed in normal condition gathered from the field data (rpm). $E_{a}$ is the activation energy in eV. TempMax field is the normal condition temperature gathered from the field data and it was $343 \mathrm{~K}$ or 70 degree Celsius. TempMax ${ }_{\text {test }}$ is the temperature in the ALT and it was set at $363 \mathrm{~K}$ or 90 degree Celsius. The AF and the accelerated test time for the front axle assembly are shown in Table 2 based on Eq. (2). Through the application of AF, the accelerated test time could be compressed and results could be obtained faster. For front axle assembly, the accelerated test time is 250 hours to guarantee $\mathrm{B}_{10}$ life of 4,000 hours.

Table 2. AF for front axle assembly.

\begin{tabular}{|c|c|c|c|c|c|}
\hline $\begin{array}{c}\text { Torq }_{\text {field }} \\
(\mathrm{kgf.m})\end{array}$ & $\begin{array}{c}\text { Torq }_{\text {test }} \\
(\mathrm{kgf.m})\end{array}$ & $\begin{array}{c}\text { Rev }_{\text {field }} \\
(\mathrm{rpm})\end{array}$ & $\begin{array}{c}\text { Rev }_{\text {test }} \\
(\mathrm{rpm})\end{array}$ & $\mathrm{AF}$ & $\begin{array}{c}\text { Accelerate } \\
\mathrm{d} \text { test time }\end{array}$ \\
\hline 191.8 & 350 & 26.1 & 26.8 & 56.6 & $250 \mathrm{hrs}$ \\
\hline
\end{tabular}

\subsection{Test setup of ALT}

In general, it is required to run thousands of hours to perform tests until the failure of the weak links is identified. In order to speed up the reliability test duration, the test conditions on proving ground became more demanding, which were mainly realized by building more severe test conditions. Thus, the design must be market-valuable and the products with "too long" or "insufficient" design life are usually too costly and comatose in the market, so it is necessary to include customers' requirements for the design, development or test phases.

As for the test, only one sample was provided. The sample test consisted of differential bevel gear and reduction gear ratio of 22:1. The target of the test was the differential and the reduction gear of the bevel gear that should operate without failure during the accelerated test time. The engine was assembled and fixed with a chassis dynamometer each on both sides of the hubs on the front wheel axle, as shown in Figure 2. The DaTAQ Pro software and control system were used for chassis dynamometer driving torque load control. With the engine on maximum speed condition at each gear level, equivalent load was applied as chassis dynamometer's constant driving load torque at the rear wheels during the accelerated test.

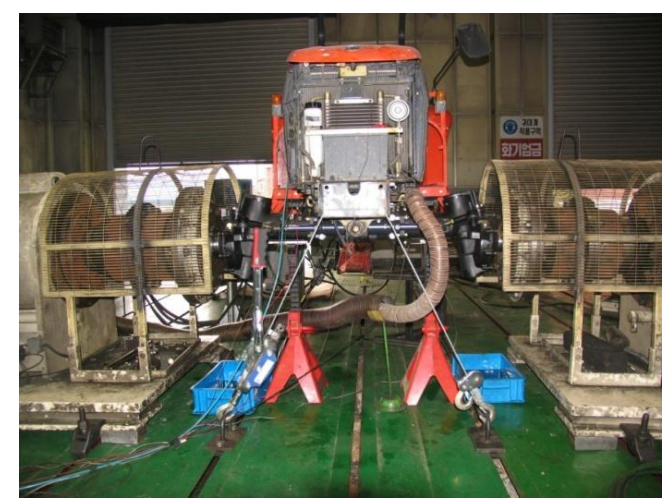

Figure 2. Test setup for front axle assembly.
Front axle assembly is shown in Figure 3 which consists of four main gears $17 \mathrm{~T}, 11 \mathrm{~T}, 40 \mathrm{~T}$ and $10 \mathrm{~T}$. During the test, the condition for all these gears needs to be observed. Any damaged occurred to the gears is considered as failure and test need to be repeated.

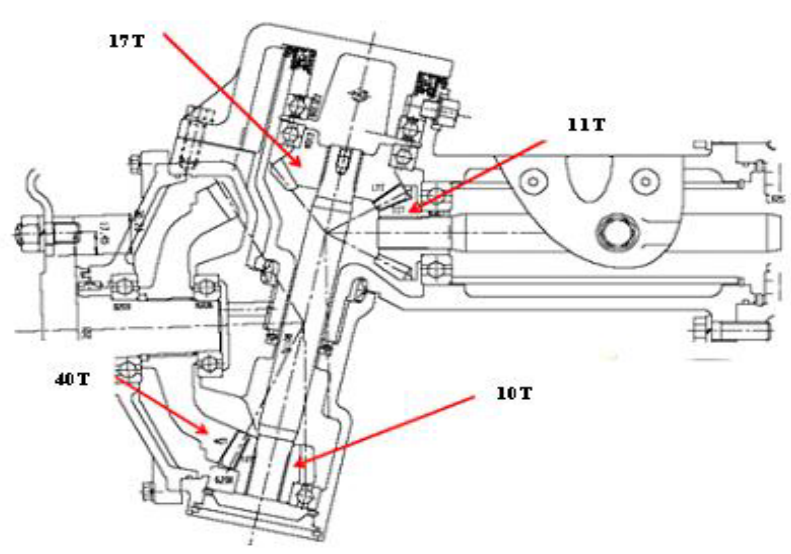

Figure 3. Schematic diagram for front axle assembly.

\section{Results and discussions}

As for the front axle assembly, the first two tests had to be stopped before the accelerated test time due to failure. From Table 3, the first failure for the test was due to the damaged $10 \mathrm{~T}$ and $40 \mathrm{~T}$ gear at 70.8 hours, as shown in Figure 4. Since the required accelerated test time is 250 hours, another test was conducted on the same sample after repaired

Table 3. Results from the first test for front axle assembly.

\begin{tabular}{|l|l|}
\cline { 2 - 2 } \multicolumn{1}{c|}{} & \multicolumn{1}{c|}{ Results } \\
\hline $\begin{array}{l}\text { Test time and } \\
\text { progress }\end{array}$ & 70.8 hours \& $28.3 \%$ \\
\hline Failure & 10T and 40T gear damage \\
\hline $\begin{array}{l}\text { Root cause } \\
\text { analysis }\end{array}$ & $\begin{array}{l}\text { Assumption of poor quality } \\
\text { condition of gear meshing during } \\
\text { applied load }\end{array}$ \\
\hline Countermeasure & $\begin{array}{l}\text { Review and inspect of the related } \\
\text { case flow and gear parts }\end{array}$ \\
\hline
\end{tabular}
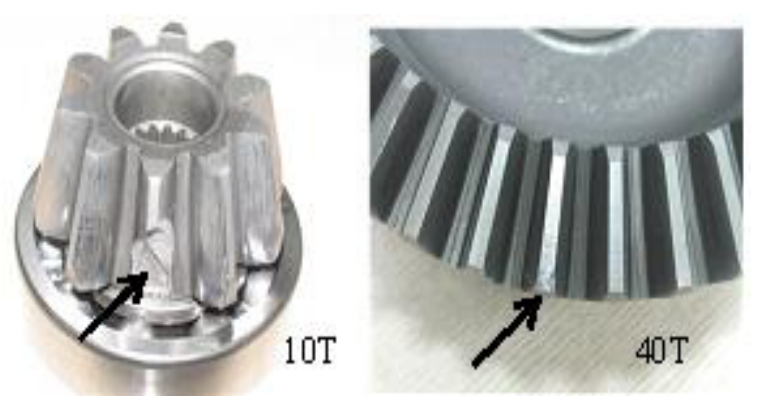

Figure 4. 10T and 40T gear tooth breakage from the first test 
From Table 4, the second failure of the test was due to the damaged 10T gear at 146.1 hours, as shown in Figure 5 for second test. Since the required test time is 250 hours, another test was conducted on the same sample after repaired.

Table 4. Results from the second test for the front axle

\begin{tabular}{|l|l|}
\multicolumn{1}{c|}{} & \multicolumn{1}{c|}{ assembly. } \\
\cline { 2 - 2 } \multicolumn{1}{c|}{$\begin{array}{l}\text { Test time and } \\
\text { progress }\end{array}$} & 146.1 hours \& $58.4 \%$ \\
\hline Defect location & 10 T gear damage \\
\hline Root cause analysis & $\begin{array}{l}\text { Severe gearing coupling } \\
\text { symptoms occurred while } \\
\text { applying load }\end{array}$ \\
\hline Countermeasure & $\begin{array}{l}\text { Gearing was changed from } \\
\text { fine-tune to shim method } \\
\text { (40T gear bearing assembly } \\
\text { part applied shim method). } \\
\text { Re-checked the assembly } \\
\text { quality characteristics table } \\
\text { and revise. }\end{array}$ \\
\hline
\end{tabular}

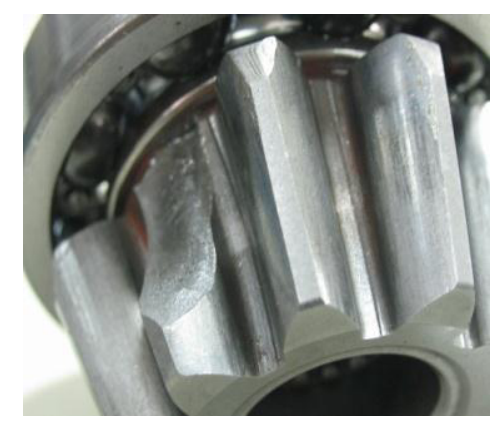

Figure 5. 10T gear tooth breakage from the second test.

As for the third test, no failure occurred after 250 hours of the test time. Thus, the result showed that the $\mathrm{B}_{10}$ life of 4,000 hours was guaranteed for the front axle assembly for powertrain with $90 \%$ confidence level. On final improvement, the shim value was adjusted for $10 \mathrm{~T}$ and $40 \mathrm{~T}$ for backlash and abutting position level for the bevel gear inside the front axle assembly as summarized in Table 5. The front axle assembly was operated without failure once the recommended improvement was implemented. Moreover, the $\mathrm{B}_{10}$ life of 4,000 hours was guaranteed with $90 \%$ confidence level. As in Figure 6, no sign of gear damage was detected after the third test from the post mortem.

Table 5. Recommended improvement.

\begin{tabular}{|c|c|}
\hline Current standard & Improvement \\
\hline $\begin{array}{l}\text { Checked bevel gear backlash } \\
\text { and abutting position level } \\
\text { inside the front axle case } \\
\text { Regulation criteria: } 0.15 \text { to } \\
0.35 \mathrm{~mm}\end{array}$ & $\begin{array}{l}\text { Adjusted shim value: } \\
\text { 40T bevel gear part: } 0.4 \mathrm{t} \\
\text { 10T bevel gear part: } 1.6 \mathrm{t}\end{array}$ \\
\hline
\end{tabular}

\section{Conclusions}

It is inconvenience to test according to the normal test time required which is 14,166 hours for the front axle assembly to guarantee $\mathrm{B}_{10}$ life of 4,000 hours with $90 \%$ confidence level. By designing an ALT, the time required is 250 hours for closely demonstrating the front axle assembly's life. The ALT has been conducted three times which finally emerged with failure free results.

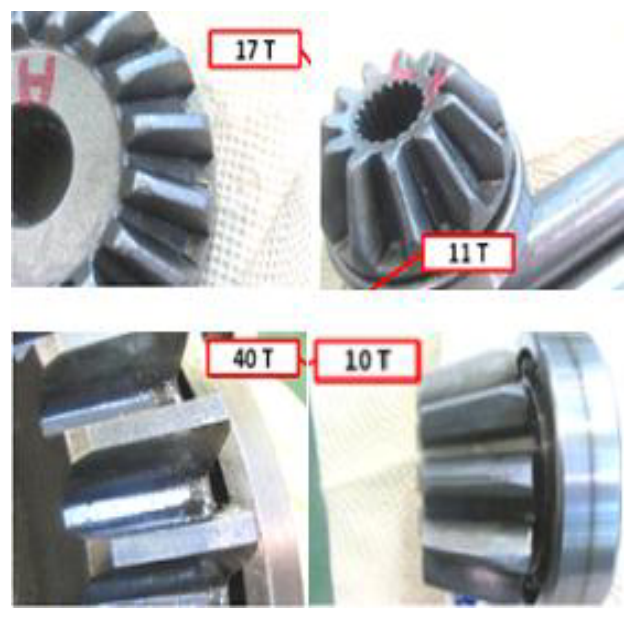

Figure 6. Examination of the gears after the third test.

Each time the test failed, some improvements such as adjustment of shim values and level or position of the gears need to be made. None of the gears involved showed any damaged in the third test after 250 hours. Thus, it can be concluded the front axle assembly $\mathrm{B}_{10}$ life of 4,000 hours with $90 \%$ confidence level is guaranteed. The result obtained from this test was useful in predicting the reliability of the front axle assembly. ALT programs should be designed and conducted by teams including knowledgeable individuals about the product and its use environments, the physical/mechanical aspects of failure mode, and the statistical aspects of the design and analysis of reliability testing.

\section{Acknowledgements}

The authors would like to be obliged to Daegu University for providing laboratory facilities and financial assistance.

\section{References}

1. M.J. LuValle, Identifying Mechanisms That Highly Accelerated Tests Miss, IEEE Trans Reliab, 56, 349-59 (2007).

2. I.F. Campean, A.J. Day, S. Wright, Camshaft timing belt reliability modelling, Proc. Int. Symp. Prod. Qual. Integr. IEEE; 377-83 (2001).

3. W.Q. Meeker, L.A. Escobar, Y. Hong, Using Accelerated Life Tests Results to Predict Product Field Reliability, Technometrics, 51, 146-61 (2009). 
4. L. Attardi, M. Guida, G. Pulcini, A mixedWeibull regression model for the analysis of automotive warranty data, Reliab Eng Syst Saf, 87, 265-73 (2005)..

5. K. Renius, Application of cumulative damage theory to agricultural tractor design elements. Konstruktion, 29, 85-93 (1977).

6. D.C. Kim, I.H. Ryu, K.U. Kim, Analysis of tractor transmission and driving axle loads. Trans ASAE, 44, 751-757 (2001).

7. Z.Q. Xi,Z.L. Zhou, Y. Li, Fuzzy Control Strategy of Powershift Transmission of Tractor, Appl Mech Mater, 241, 1959-63 (2013).

8. W. Jung, A. Ismail, Method of Determining Acceleration Factors for Agricultural Tractors, Qual. Reliab. Risk, Maintenance, Saf. Eng. IEEE, 346-348 (2011).

9. B. Bertsche, G. Lechner, Reliability in Automotive and Mechanical Engineering. Berlin: Springer Berlin Heidelberg, (2008).

10. J.W. Evans, J.Y. Evans, editors, Product Integrity and Reliability in Design, London: Springer-Verlag, (2001).

11. L.A. Escobar, W.Q. Meeker, A Review of Accelerated Test Models. Stat Sci, 21, 552-577 (2006). 